\title{
(2) consen \\ ○ OPEN ACCESS \\ Ischaemic stroke and pre-eclampsia in the third trimester of pregnancy: a diagnostic and therapeutic challenge
}

\author{
Alexandros Loukas Grammatis, ${ }^{1}$ Hannah Louise Catton, ${ }^{2}$ Derek Hilton ${ }^{3}$
}

'Obstetrics and Gynaecology, Buckinghamshire Healthcare NHS Trust, Ayelsbury, UK

${ }^{2}$ Anesthetics, Buckinghamshire Healthcare NHS Trust, Ayelsbury, UK

${ }^{3}$ Neurology, Wexham Park Hospital, Wexham, UK

Correspondence to Alexandros Loukas Grammatis; alexgrammatis@gmail.com

Accepted 23 November 2019
Check for updates

(c) BMJ Publishing Group Limited 2020. Re-use permitted under CC BY-NC. No commercial re-use. See rights and permissions. Published by BMJ.

To cite: Grammatis AL, Catton HL, Hilton D. BMJ Case Rep 2019;12:e229635. doi:10.1136/bcr-2019229635

\section{SUMMARY}

A 23-year-old low-risk primiparous patient, who was 35 weeks pregnant, presented in the emergency department after collapsing at home. Her observations showed severe hypertension with proteinuria. On examination, she had left hemiparesis and was aphasic. Fetal monitoring was reassuring. Initial CT did not reveal any evidence of intracranial pathology. She was stabilised and delivered via emergency caesarean section. Subsequent MRI and CT showed an acute right-sided infarct involving the right middle cerebral artery territory, frontal and parietal regions, and increased mass effect. She was transferred to the nearest neurosurgical centre where she was conservatively managed and discharged home 3 weeks later for continuing rehabilitation. She achieved a good recovery.

\section{BACKGROUND}

Recognising and managing hypertension in pregnancy is the bread and butter of obstetricians worldwide. However, managing the rare and sometimes catastrophic neurological consequences of pregnancy-induced hypertension or pre-eclampsia can prove a diagnostic and multidisciplinary challenge. This case demonstrates how recognising the need for prompt transfer to an appropriate critical care environment, organising the necessary imaging, having appropriate discussions and then acting on the results is critical for providing optimal care and ultimately achieving good outcomes for these patients.

\section{CASE PRESENTATION}

A 23-year-old woman who was 35 weeks pregnant presented to the emergency department after her husband had found her collapsed at home. There was no witnessed seizure activity and no suggestion of previous episodes. This, her first pregnancy, had thus far been low risk but she had missed a community antenatal appointment at 32/40 weeks. Her booking blood pressure was 100/60 mm Hg.

The patient was previously fit and well with no significant medical history, and she took no regular medications. She lived at home with her husband and parents-in-law, was a non-smoker and did not drink alcohol. There was no family history of VTE or stroke.

On examination, she had dense left hemiparesis, power was $1 / 5$ in the left upper and lower limbs, and was aphasic, leading to a GCS score of $14 / 15$, demonstrating a clear neurological component to her presentation. She could communicate by writing with her right hand and was able to indicate a severe right-sided headache. She denied visual disturbances or abdominal pain. Her blood pressure was $190 / 120 \mathrm{~mm} \mathrm{Hg}$ which was relevant due to concerns about pre-eclampsia.

\section{INVESTIGATIONS}

Initial biochemical and haematological investigations, including full blood count and a clotting profile, were unremarkable. On admission, an ECG to exclude arrhythmia demonstrated normal sinus rhythm. Urinalysis showed proteinuria and subsequent PCR was elevated at 170, supporting an initial diagnosis of pre-eclampsia. An initial CT scan (figure 1) was performed to exclude intracranial bleeding and did not show any acute pathology; however, subsequent MRI imaging (figure 2) showed an acute infarct involving the right middle cerebral artery (MCA) and frontal and parietal regions. Further CT imaging 12 hours later also demonstrated increased mass effect.

After the initial acute phase, the patient was repatriated to her local stroke unit. Here, she underwent further investigation for the cause of the stroke. CT angiogram aortic arch and carotids demonstrated grossly normal anatomy other than mild attenuation of the branches of the right MCA. A transthoracic echocardiogram with agitated saline did not show any abnormalities. The thrombophilia and antiphospholipid syndrome screen were also negative.

\section{DIFFERENTIAL DIAGNOSIS}

In pregnant patients, the clinical features of ischaemic stroke are similar as in the non-pregnant patients. The proposed mechanisms that render pregnant women at increased risk of ischaemic/ thrombotic stroke are endothelial dysfunction, abnormal cerebral autoregulation resulting in higher perfusion pressures, haemoconcentration due to third spacing of intravascular fluids and activation of coagulation cascade with microthrombi formation. ${ }^{1}$ The most common obstetric aetiologies of both ischaemic and haemorrhagic stroke are pre-eclampsia, eclampsia and HELLP syndrome; the proportion of patients with a pregnancy-related stroke who have pre-eclampsia is $25 \%-45 \%{ }^{2}$ 


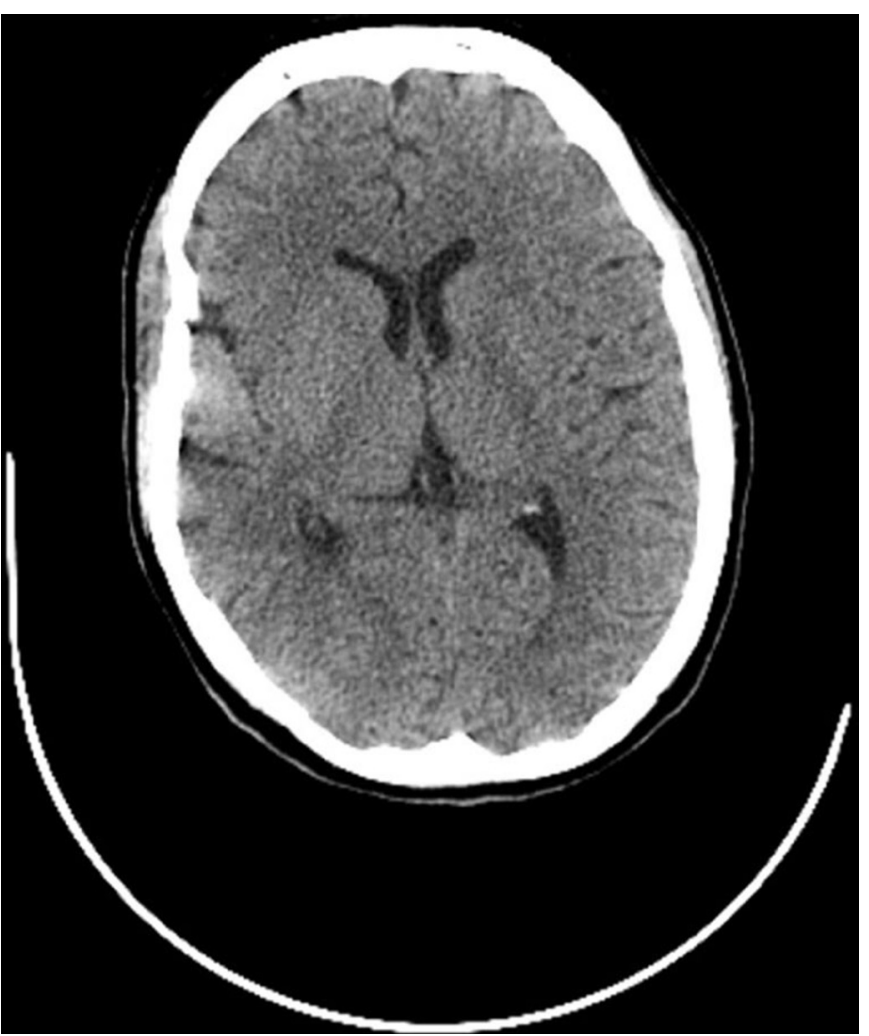

Figure 1 First CT head image after initial stabilisation of the patient.

Less common causes include cardiac causes of arterial emboli or arrhythmias, mitral valve disease, peripartum cardiomyopathy, infective endocarditis, paradoxical embolus through an atrial septal defect or patent foramen ovale, aortic/carotid artery dissection, antiphospholipid syndrome, vasculitis, sickle cell disease and thrombotic thrombocytopaenic purpura. ${ }^{3}$

Careful consideration and a multidisciplinary approach should be used to differentiate between an acute hypertensive response secondary to a stroke and severe hypertension as a result of pre-eclampsia. Stroke can result in direct injury of

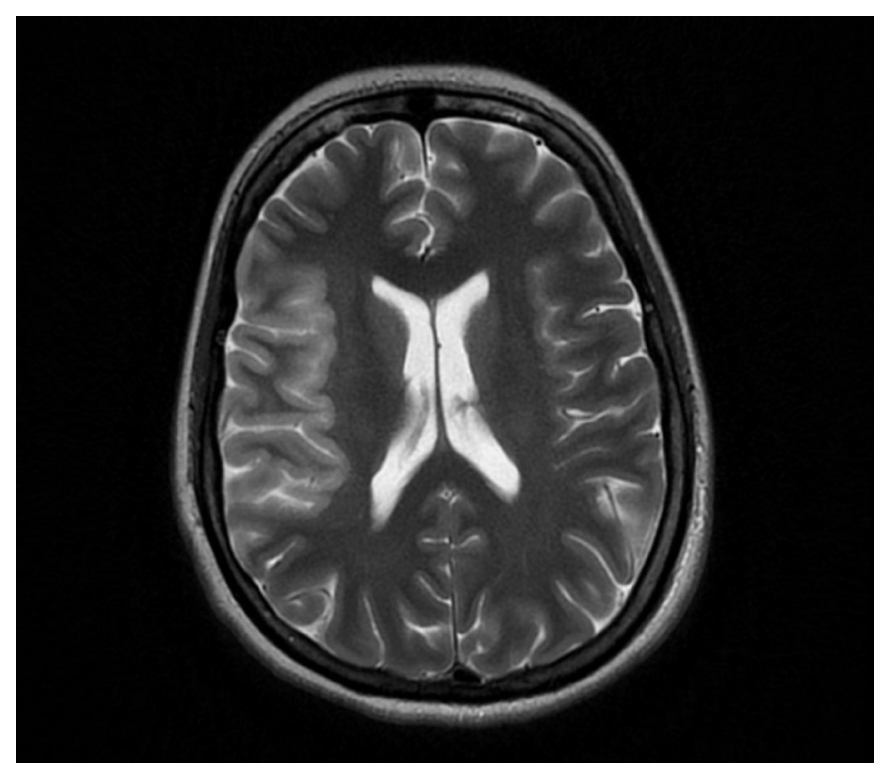

Figure 2 MRI head image showing ischaemic changes consistent with an ischaemic stroke in the right middle cerebral artery territory. autonomic inhibitory regions of the brain and reduction of parasympathetic activity. These changes lead to an abrupt increase in systemic vascular resistance and impaired carotid baroreceptor activity leading to dysregulated elevated blood pressure. ${ }^{4}$ However, severe hypertension (>160/100 mm Hg) combined with significant proteinuria (urine protein:creatinine ratio of more than $30 \mathrm{mg} / \mathrm{mmol}$ ) in pregnancy is associated with severe pre-eclampsia and the aim should be a gradual reduction of the blood pressure.

Risk factors for stroke in non-pregnant patients, such as hypertension, diabetes and smoking, are found less commonly in pregnancy-related stroke. Clinicians should, however, be aware of an association with a history of migraines, gestational diabetes and aforementioned pre-eclampsia. ${ }^{5}$

Main differential diagnoses include intracerebral haemorrhage, subarachnoid haemorrhage, cerebral venous thrombosis, posterior reversible encephalopathy syndrome and reversible cerebral vasoconstriction syndrome. The first imaging modality is usually a head CT scan, as it is both readily available and can differentiate haemorrhage from infarction. However, brain MRI is more sensitive for the detection of small infarcts and the visualisation of very early infarction when diffusion-weighted imaging is used. ${ }^{6}$ MR venography (MRV) can also be considered to diagnose cerebral venous sinus thrombosis. However, sinus thrombosis usually presents as an evolving severe focal headache, only very late in its course might a stroke (and hence focal neurological deficits) occur. Given that the patient's presentation was a sudden focal neurological deficit, it was appropriate to be suspicious of stroke and not sinus thrombosis. Hence, an MRV was not indicated in this case. Echocardiography and carotid Doppler studies may be useful if clinical findings suggest cardiac or carotid pathology. Blood investigations, including full blood count, biochemical studies, peripheral blood smear, clotting profile and thrombophilia screen, can help in pointing towards the right diagnosis.

\section{TREATMENT}

Blood pressure was controlled with intravenous labetalol, aiming for a gradual reduction of $15 \%-25 \%$. A total of $4 \mathrm{~g}$ of intravenous magnesium sulfate was also administered as a bolus, followed by an infusion of $1 \mathrm{~g} /$ hour for 24 hours, for eclamptic seizure prophylaxis.

After the patient was stabilised and the CT head excluded a haemorrhagic stroke, the decision was taken to deliver the fetus by caesarean section, given the diagnosis of severe preeclampsia. This was after extensive discussion between obstetric teams in both secondary and tertiary centres, anaesthetic teams, stroke physicians and neurology physicians. We administered one dose of intramuscular betamethasone $(12 \mathrm{mg})$ for fetal lung maturation.

Anaesthetic technique was considered from two approaches; the logistics of performing neuraxial versus general anaesthetic, and the physiological implications of these in turn. In light of unclear intracranial pathology with labile blood pressure, this woman was deemed not to be a candidate for neuraxial anaesthetic. She could also not be positioned safely. Hence, the procedure was performed under general anaesthetic. The patient's blood pressure was monitored non-invasively and intravenous labetalol was titrated with good effect. It was decided that invasive blood pressure monitoring would not be necessary at this point. A modified rapid sequence approach was taken; propofol and $1.2 \mathrm{mg} / \mathrm{kg}$ of rocuronium were used to induce general anaesthesia and to obtain good intubating conditions. Fentanyl was 
used as a co-induction agent; $200 \mu \mathrm{g}$ at induction was adequate to attenuate the response to laryngoscopy. Anaesthesia was maintained with the volatile agent sevoflurane. Standard caesareansection drugs were also administered throughout the procedure, including antibiotics (cefuroxime and metronidazole). The operation was uneventful with an estimated blood loss of $500 \mathrm{~mL}$. The blood pressure intraoperatively was between $120-130 \mathrm{~mm}$ $\mathrm{Hg}$ over $80-90 \mathrm{~mm} \mathrm{Hg}$. The baby was born in good condition and did not need admission to the special care baby unit. This woman was very slow to wake and was extubated successfully around $90 \mathrm{~min}$ postprocedure. Arterial blood gas analysis was unremarkable.

The patient was later transferred to ITU and was reintubated for a head MRI, which confirmed a right-sided MCA ischaemic stroke. Her blood pressure in ITU continued to be stable, while on intravenous labetalol, with average values between $130-140 \mathrm{~mm} \mathrm{Hg}$ over $80-90 \mathrm{~mm} \mathrm{Hg}$. The next day, the repeat CT head showed increased mass effect with low attenuation in the right frontal-parietal cortex, now extending to the basal ganglia. The decision was taken then to transfer the patient to the nearest tertiary centre for a possible hemicraniectomy. Surgery was halted in favour of conservative management; however, the patient had ongoing oxygen desaturations. A CTPA excluded a pulmonary embolus; however, it showed pneumonia and she was started on intravenous co-amoxiclav. She was transferred back to the local unit 3 days later for stroke rehabilitation. She was treated with aspirin and low-molecular weight heparin. Aspirin was switched to clopidogrel after 14 days. She was also started on ramipril to control her blood pressure. She received intense rehabilitation with physiotherapy, occupational therapy, and speech and language therapy.

\section{OUTCOME AND FOLLOW-UP}

This patient has made excellent progress. Her speech returned fully, and she has regained full power and movement of her left lower limb. Six weeks poststroke, there is only minimal weakness of her left upper limb, mainly her forearm. Ramipril was also stopped 6 weeks postoperatively as the blood pressure was well-controlled.

She was counselled that the risk of recurrent ischaemic stroke was low in future pregnancies, with one study showing a risk of $2 \%$, which is not statistically different from outside pregnancy. ${ }^{7}$

She will be managed with low-dose aspirin and low-molecular weight heparin in future pregnancies to prevent the risk of recurrent pre-eclampsia and thrombosis.

\section{DISCUSSION}

Antenatal stroke is a rare entity with an estimated incidence of 1.5 per 100000 women delivering in the UK. Poor outcomes have been reported with a case fatality rate of $20 \%$ of all strokes. ${ }^{5}$ To this day, there is a wide discrepancy in the treatment of stroke in pregnancy.

MBRRACE guidelines support that pregnancy should not alter the standard of care for women with a stroke and that all women should be initially admitted to a hyperacute stroke unit. ${ }^{8}$ The diagnosis in this patient was unclear and it was felt safer for her to be taken to an area of obstetric care. However, a learning point from this case would be to seek advice from and possible admission to a tertiary centre with both obstetric and acute stroke services available, if a stroke was suspected in an obstetric patient.

Studies have shown that the use of thrombolysis in pregnancy is safe, without any significant increase in maternal deaths or major bleeding events. ${ }^{9-11}$ However, haemorrhage during parturition or caesarean delivery is a particular risk with fibrinolytic therapy if the patient goes into labour or operative delivery is required, so the benefits of such treatment must be carefully weighed against the risks, particularly in cases of severe preeclampsia, when delivery must be expedited.

High-quality evidence has shown that mechanical thrombectomy is superior to standard treatment with intravenous thrombolysis alone for ischaemic stroke caused by a documented large artery occlusion in the proximal anterior circulation, which is the most common type of ischaemic stroke in pregnancy. ${ }^{12}$ The evidence for its use in pregnancy is limited, but case reports have been reassuring. ${ }^{13}$ It may be preferred over intravenous thrombolytic therapy for women considered to have a high risk of haemorrhage. New guidelines from the American Heart Association also advise that it can be performed up to 24 hours after the diagnosis of stroke. ${ }^{14}$ Unfortunately, adoption of thrombectomy has been slow in the UK, compared with the USA, Germany and France. However, over 400 patients received thrombectomy in England, Wales and Northern Ireland in 2015-2016. ${ }^{15}$

For women with severe pre-eclampsia leading to a stroke, such as in our case, the usual management would be to stabilise them and deliver the baby first, to prevent further deterioration of the mother. Evidence for what the optimal management of ischaemic strokes caused by pre-eclampsia should be is scarce. Careful consideration should be given in these cases to the possibility that proteinuria can be the result of severe hypertension exceeding a critical limit and leading to malignant nephrosclerosis, rather than pre-eclampsia causing proteinuria, although the evidence is not very clear. ${ }^{16}$ What is certain is that close liaison between the obstetric, anaesthetic and neurology teams is needed for these patients to decide the safest approach initially for the mother and subsequently for the fetus. In our case, the outcome was good despite thrombolysis not being administered or mechanical thrombectomy being performed, but the patient was considered for and almost required neurosurgical intervention. Early recognition and timely transfer to a tertiary centre ensured that the best available care was offered to the patient and contributed to the good outcome.

\section{Learning points}

A multidisciplinary approach, with a discussion between obstetricians, neurologists and anaesthetists, is imperative to manage a suspected stroke in pregnancy.

- Antihypertensive treatment in obstetric patients with acute stroke is only recommended if the diagnosis of pre-eclampsia is confirmed.

- The initial place of assessment should be the hyperacute stroke unit when possible. Ideally, this should be in a tertiary centre where both obstetric and stroke services are available.

Acknowledgements We would like to thank Shaku Kalla (Obstetric Consultant) and Dr Dinesh Selvan (Anaesthetic Consultant) who were both involved in this case and offered fundamental advice about the management of this patient. We would also like to extend thanks to Dr Hilton (Consultant Neurologist) for his valuable contribution in writing up this case.

Contributors The report was written solely by ALG and HLC. Edited and supervised by DH.

Funding The authors have not declared a specific grant for this research from any funding agency in the public, commercial or not-for-profit sectors.

Competing interests None declared.

Patient consent for publication Obtained.

Provenance and peer review Not commissioned; externally peer reviewed. 
Open access This is an open access article distributed in accordance with the Creative Commons Attribution Non Commercial (CC BY-NC 4.0) license, which permits others to distribute, remix, adapt, build upon this work non-commercially, and license their derivative works on different terms, provided the original work is properly cited and the use is non-commercial. See: http://creativecommons.org/ licenses/by-nc/4.0/.

\section{REFERENCES}

1 Treadwell SD, Thanvi B, Robinson TG. Stroke in pregnancy and the puerperium. Postgrad Med J 2008;84:238-45.

2 Sharshar T, Lamy C, Mas JL. Incidence and causes of strokes associated with pregnancy and puerperium. A study in public hospitals of lle de France. stroke in pregnancy Study Group. Stroke 1995;26:930-6.

3 Nelson-Piercy C. Ischaemic (non-haemorrhagic) stroke. In: Handbook of obstetric medicine. 5th edn. CRC Press, 2015: 181-2.

4 Qureshi Al. Acute hypertensive response in patients with stroke: pathophysiology and management. Circulation 2008;118:176-87.

5 Scott CA, Bewley S, Rudd A, et al. Incidence, risk factors, management, and outcomes of stroke in pregnancy. Obstet Gynecol 2012;120:318-24.

6 Lee MJ MD, Hickenbottom S MD, MS. Cerebrovascular disorders complicating pregnancy, 2018. Available: https://www.uptodate.com/contents/cerebrovasculardisorders-complicating-pregnancy?source=mostViewed_widget\#H14 [Accessed 13 Jan 2019].

7 Lamy C, Hamon JB, Coste J, et al. Ischemic stroke in young women: risk of recurrence during subsequent pregnancies. French Study Group on stroke in pregnancy. Neurology 2000;55:269-74.
8 Knight M, Tuffnell D, Kenyon S, et al, eds. Saving Lives, Improving Mothers' Care Surveillance of maternal deaths in the UK 2011-13 and lessons learned to inform maternity care from the UK and Ireland Confidential Enquiries into Maternal Deaths and Morbidity 2009-13. National Perinatal Epidemiology Unit, University of Oxford: Oxford, 2015.

9 Gartman EJ. The use of thrombolytic therapy in pregnancy. Obstet Med 2013;6:105-11.

10 Leffert LR, Clancy CR, Bateman BT, et al. Treatment patterns and short-term outcomes in ischemic stroke in pregnancy or postpartum period. Am J Obstet Gynecol 2016;214:723.e1-723.e11.

11 Sousa Gomes M, Guimarães M, Montenegro N. Thrombolysis in pregnancy: a literature review. J Matern Fetal Neonatal Med 2019;32:2418-28.

12 Campbell BCV, Donnan GA, Lees KR, et al. Endovascular stent thrombectomy: the new standard of care for large vessel ischaemic stroke. The Lancet Neurology 2015;14:846-54.

13 Bhogal P, Aguilar M, AlMatter M, et al. Mechanical thrombectomy in pregnancy: report of 2 cases and review of the literature. Interv Neurol 2017;6:49-56.

14 Powers WJ, Rabinstein AA, Ackerson T, et al. 2018 guidelines for the early management of patients with acute ischemic stroke: a guideline for healthcare professionals from the American heart Association/American stroke association. Stroke 2018;49:e46-99.

15 Stroke Association. State of the nation, stroke statistics, 2018. Available: https://www. stroke.org.uk/system/files/sotn_2018.pdf [Accessed 13 Jan 2019].

16 Griffin KA, Polichnowski A, Litbarg N, et al. Critical blood pressure threshold dependence of hypertensive injury and repair in a malignant nephrosclerosis model. Hypertension 2014;64:801-7.

Copyright 2020 BMJ Publishing Group. All rights reserved. For permission to reuse any of this content visit

https://www.bmj.com/company/products-services/rights-and-licensing/permissions/

BMJ Case Report Fellows may re-use this article for personal use and teaching without any further permission.

Become a Fellow of BMJ Case Reports today and you can:

- Submit as many cases as you like

- Enjoy fast sympathetic peer review and rapid publication of accepted articles

- Access all the published articles

Re-use any of the published material for personal use and teaching without further permission

Customer Service

If you have any further queries about your subscription, please contact our customer services team on +44 (0) 2071111105 or via email at support@bmj.com.

Visit casereports.bmj.com for more articles like this and to become a Fellow 